\title{
DESCRIPTIVE AND EXPERIMENTAL CYTOLOGY IN ALLIUM
}

\author{
III. DEFICIENCY OF SATELLITES IN \\ THE NUCLEOLAR CHROMOSOMES
}

\author{
Yukio Kato \\ Biological Institute, Faculty of Science, Nagoya University, Nagoya, Japan
}

Received May 21, 1955

UDC 582. 572. $2: 576.312$. $32: 576.3$.

During the study on the effects of various chemicals on root-tip cells in Allium fistulosum, some plants having new karyoty pes were found. As is well known, somatic chromosome complement of Allium fistulosum consists of 16, a pair of which bearing nucleoli and big satellites. The material used in the present investigation was collected from the field of Kiyosu, the suburbs of Nagoya, Central Japan. This local variety is called "Wakeginebuka". The other material is a commercial variety "Kujonegi", which is cultivated in the field of Aichi and Gifu prefecture. Root tips were fixed with Carnoy's fluid without chroloform, stained by aceto-orcein technique. Meioses in pollen mother cells and mitoses in pollen grains were observed with acetocarmine smears. Nucleoli attached to the nucleolar chromsomes were distiguished easily from the other components, in the cells stained with pyronin-methylgreen, thionine or tholuidine blue.

The work has been carried out under the direction of Dr. T. Shimamura of the Nagoya University to whom the author wishes to express his sincere gratitude. To Dr. H. Ono of the Tokyo Metropolitan University the author is indebted as well for his critical reading of the manuscript.

\section{Observations}

I. Mitosis in the root-tip cells

In usual plants, a pair of nucleolar chromosomes is found, which are denoted here as SS. Fig. 1 shows the linear arrangement of the somatic chromosomes in order of their lenghs and the nucleolar chromosomes are placed at the extreme right. On the other hand, all the investigated plants of the variety "Wakeginebuka" have been found to be heterozygous for satellites of the nucleolar chromosomes, and may be designated as karyotype $\mathrm{SS}^{-}$, i. e., one of the nucleolar chromosome pair is completely devoid of its entire satellite including the stalk, and the other is normally satellited (Figs. 2, 4 and 5). In all the chromosome pairs, except the nucleolar chromosome pair, partners are morphologically indistiguishable from those of cells in usual plants. 
The number of the nucleoli per nucleus vary from one to two with the frequency of 20 and 32 cells respectively. This frequency was based on random counts on resting nuclei. Some plants of the variety "Kujonegi" have been found to be homozygous for deficiency of satellite of the nucleolar chromosomes (Figs. 3 and 9). It may be designated as karyotype $\mathrm{S}^{-} \mathrm{S}^{-}$. In root-tip cells the maximum number of nucleoli is

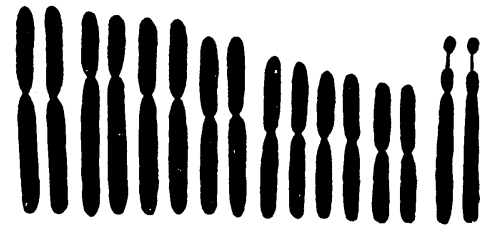

A A B B C C D D E E F F G $S \mathrm{~S}$

1

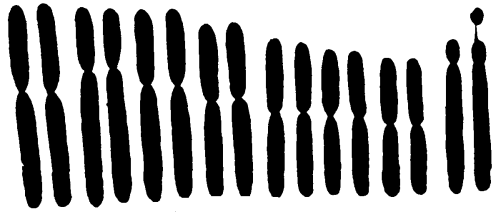

A A B B C C D D E E F G G S S

2

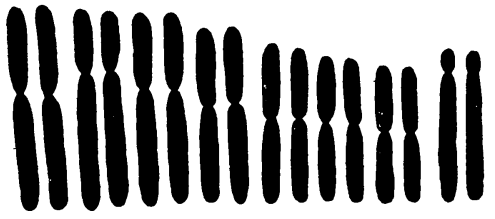

A A B B C C D D E E F F G G S

3

Figs. 1-3. Serial aligments of somatic chromosomes of Allium fistulosum. The nucleolar chromosomes are placed at the extreme right. 1. The variety "Kujonegi". 2. The variety "Wakeginebuka". 3. The variant from the variety "Kujonegi ",

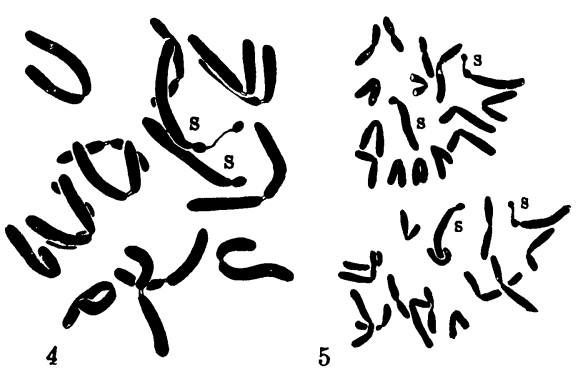

n d

6

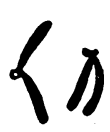

$l_{c} V_{0}$
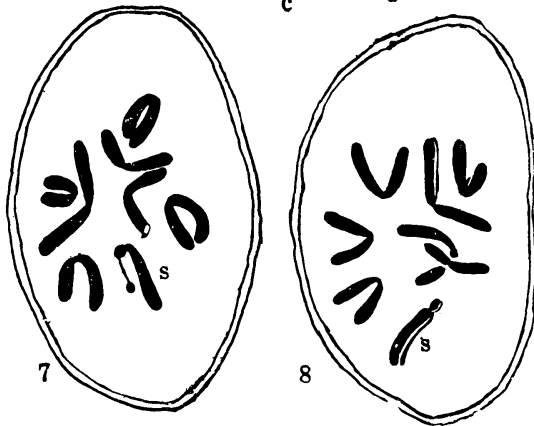

Figs. 4-8. The variety "Wakeginebuka". 4. Somatic metaphase. 5. Somatic anaphase. 6. a-b. Pairing of the nucleolar chromosomes in the meiotic metaphase. c-d. Separation of the nucleolar chromosomes in the meiotic anaphase. 7-8. Pollen mitosis. " $\mathrm{S}$ " represent the nucleolar chromosomes.

two, irrespective of the karyotyp:c alternation. Among about 20 plants examined, 17 were revealed to be of karyotype SS and the remaining $3 \mathrm{~S}^{-} \mathrm{S}^{-}$. The plants with the karyotype $\mathrm{S}^{-} \mathrm{S}^{-}$had not flowered until 1953 since the transplanting of the adult plant in 1950, and flowered in August, 1954. The plants with SS- karyotype are not different from the usual plants in the flowering habit.

II. Fragmentation in root-tip cells

In the root tips of $\mathrm{SS}^{-}$karyotyped plants, chromosome fragments in anaphase 
were seldom met with (Figs. 12 and 13). This occurrence is about $0.1 \%$. They are seemingly a satellite fragment, as the size of the fragment is invariable in different root-tip cells. Although such satellite-like fragments have often been found in seedlings of Aliium fistulosum by the author (Kato 1954), it has not hitherto found with the root-tip cells of grown-up plants of this species. In SS and $\mathrm{S}^{-} \mathrm{S}^{-}$karyotyped plant, on the other hand, satellite or satellite-like fragments could never be detected.

\section{Meiosis}

In pollen mother cells eight bivalents are invariable formed in all three karyotypes, and meiosis proceeds quite regulariy, except cccational failure of pairing in $\mathrm{SS}^{-}$or $\mathrm{S}^{-} \mathrm{S}^{-}$pairs. The univalents are distributed at random in the cytoplasm. Heteromorphic pair SS- shows two different figures at first metaphase in respect to
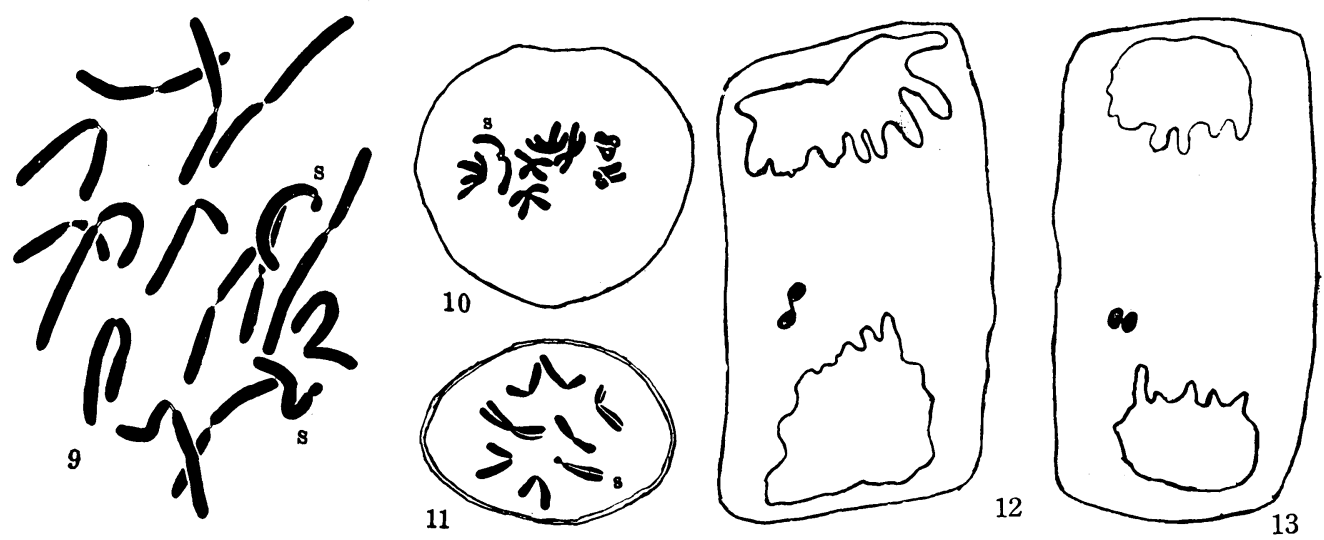

Figs. 9-11. The variant from the variety "Kujonegi". 9. Somatic metaphase. 10. Meiotic metaphase. 11. Pollen mitosis. " $\mathrm{S}$ " represent the nucleolar cnromosomes. 1213. Satellite-like fragments in the root-tip cells of the variety "Wakeginebuka".

its short arm pair. One is the figure showing a single large protrusion from the paired kinetochores, which is now called "type I" (Fig. 6a). The other is one having two protrusions, instead of one, of which one being large and the other markedly small in size, which is called "type II" (Fig. 6b). Larger protrusion represents obviously the satellited arm of chromosome $\mathrm{S}$, and the small one the short arm of non-satellited chromosome $\mathrm{S}^{-}$. The frequency of occurrence of type I and II in the first metaphase is 65 to 41 . At the first anaphase, two different modes of separation are easily distinguishable according to whether the two satellited cnromatids pass to the same pole (Fig. 6d) or separate to opposite poles (Fig. 6c). The frequencies of these two modes of separation are 78 and 20 respectively. According to the Matsuura's neo-two-plane theory, the frequency of type I must cccur twice as frequent as type II. In the present data there is a great discrepancy from the expectation. But since the divergence of the actual ratio from the expectation has been ingeniously explained by Haga (1944), the author will leave it untouched. The short arm of $\mathrm{S}^{-} \mathrm{S}^{-}$chromosome pairs shows two small protrusions from the synaped kinetochore (Fig. 10). 
This protrusion represents the non-satellited short arm of nucleolar chromosome. In anaphase they separate quite regularly to the pole.

\section{Pollen mitosis and pollen fertility}

At the metaphase of pollen mitosis eight chromosomes are found in all three karyotyped plants. In ordinary plants, one nucleolus and one chromosome S are always found. SS- karyotype produces two kinds of pollen grains (Figs. 7 and 8). Among 119 pollen grains examined, 62 contain chromosome $\mathrm{S}$ and 57 contain chromosome $\mathrm{S}^{-}$giving nearly $1: 1$ ratio at the primary mitosis. It was also found that at prometaphase, nucleolus is always attached to the "S" type chromosome. On other words, irrespective of the presence $(\mathrm{S})$ or absence $\left(\mathrm{S}^{-}\right)$of the satellite, the " $\mathrm{S}$ " type chromosome is the sole nucleolar chromosome in the component. The same condition was observed also with the case of $\mathrm{S}^{-} \mathrm{S}^{-}$karyotyped plants. Fig. 11 shows the metaphase of pollen mitosis. Average percentage of pollen fertility in SS, SSand $\mathrm{S}^{-} \mathrm{S}^{-}$karyotyped plants is respectively 98.3, 96.5 and 97.7. It is, therefore, evident that there is no direct correlation between the pollen fertility and the absence or presence of the satellite.

\section{Somatic chromosomes and morphological characters in the progeny of the selfed $\mathbf{S S}^{-}$plants}

When the $\mathrm{SS}^{-}$plants are selfed, it is expected that SS, $\mathrm{SS}^{-}$and $\mathrm{S}^{-} \mathrm{S}^{-}$plants occur with $1: 2: 1$ ratio. Mitoses in the progenies of 23 individuals obtained from three selfed plants were studied in 1953. The following table shows the frequency of the cccurrence of each type (Table 1). It is obvious that there is a close rela-

Table 1 The progeny obtained by selfing from $\mathrm{SS}^{-}$karyotyped plants

\begin{tabular}{l|ccccc} 
& $\mathrm{SS}$ & $\mathrm{SS}^{-}$ & $\mathrm{S}^{-} \mathrm{S}^{-}$ & $\begin{array}{c}\text { Exceptional } \\
\text { plant }\end{array}$ & Total \\
\hline $\begin{array}{l}\text { Number of } \\
\text { cases }\end{array}$ & 4 & 11 & 7 & 1 & 23 \\
$\begin{array}{l}\text { Average number } \\
\text { of tillers }\end{array}$ & 2.7 & 19.2 & 18.7 & 16 & - \\
\hline
\end{tabular}
tionship between the number of tillers and the absence of satellites. Average number of tillers in the mother plants was 18.1. One exceptional plant appeared in the progeny from the selfed $\mathrm{SS}^{-}$plants. In the root-tip cells of this plants, two different karyotypes were found in the chimeral state. One is that having chromosome $\mathrm{SS}^{-}$and the other having $\mathrm{S}^{-} \mathrm{S}^{-}$. The majority of cells was observed to have chromosome SS-. This condition suggests that fragmentaions have taken place at the attachment fibre of the nucleolar cinromosomes. Meiosis in the pollen mother cells and pollen mitosis of this p.ant could unfortunately not examined because the plant failed to survive. In $\mathrm{SS}^{-}$plants obtained by selfing from $\mathrm{SS}^{-}$plants, the majority of metaphase plates which could be counted had 16 chromosomes. But a few cells were observed which clearly had 32 chromosomes, and several others in which counts of 29-32 could be estimated. In some cells, each of 16 chromosome appeared paied, and united at a single kinetochore. The dipolid. tetraploid chimera in heterozygocity poses an interesting problem. 


\section{Chromosome fragmentation by pyrogallol in $\mathrm{SS}^{-}$karyotyped plants}

Therman-Soumalinen (1949) has described that pyrogallol has a weak radiomimetic effect, mainly restricted to the points of the secondary constrictions. It was tested whether pyrogallol had a selective action on the attachment fibre of chromosome $\mathrm{SS}^{-}$. The aqueous solution of concentration $0.005 \mathrm{~mol} / 1$ was employed exclusively. The maximum effect was obtained after four hours' treatment in this concentration. The fragments observed were of various size; therefore the breakage evidently cccurred at random points of all the chromosomes. The same phenomenon has been evidenced in Vicia faba treated by pyrogallol (Tjio 1951)

\section{Discussion}

A note-worthy peculiarity in the present observation concerns with the origin of new karyotypes. Almost all cases on the deficiency of satellites in the nucleolar chromosomes are the consequence of meiotic reduction. In fact, Haga (1942) has described on the karyotypic polymorphism in Paris verticiilata and on the fragmentation of satellite from chromosome $\mathrm{D}$ at meiosis. Chromosome $\mathrm{S}^{-}$found in the present investigation is obviously the result of simple deletion of the satellite of the chromosome S. It is very difficult, however, to determine whether this deficiency cccurs through meiotic or mitotic processes. As far as can be judged from the present observation, the elimination of satellite seems to cccur through mitotic process. In seedlings of Allium fistulosum, fragmentation cccurs predominantly by breaking of the attachment fibre of the satellite in the nucleolar chromosomes (Kato 1954). The fact that breaks are localized to the satellite fibre would be explained by the " nucleolar hypothesis" (Kihlmann 1952). According to this hypothesis, certain physical or chemical agents, after the entrance into nucleus, acc dmulate on intranuclear surface, e. g., the surface of the nucleolus. On such surface, the chemical or physical agents would eventually exceed their limiting concentrations for chromosome breaking. The question why fragmentation of the satellites are found only in $\mathrm{SS}^{-}$plants but not in SS or $\mathrm{S}^{-} \mathrm{S}^{-}$is yet left open. It may occur only in the plants or cells with unbalanced type of chromosomes. In recent, Ono and Sakai (1952) reported the cells with unstable karyotypes in the hybrids of Paraixeris denticulata $(2 n=10)$ and Lactuca squarosa $(2 n=18)$. The chromosome number in this hybrid is less than the sum of the parental numbers. They suggested that fragmentaion had taken place at definite loci in a definite chromosome and that the diminution had resulted in a balanced state of the chromosome. This hypothesis seems to be supported by the present observation also. The morphological chracters of $\mathrm{S}^{-} \mathrm{S}^{-}$karyotyped plants produced by selfing of

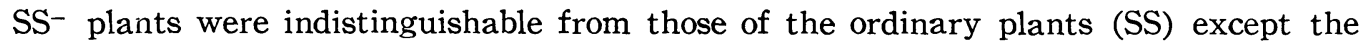
time of flowering. The former flowers later than the latter. The variety "Wakeginebuka" which has SS- karyotype is now exclusively propagated by vegetatives (bulbs), irrepective of the production of good seeds.

It was often reported that the asymmetry or elimination of satellites is ac- 
companied by deviation of some morphological or physiological characters as seen in Galtonia, Muscari, Crepis or Paris etc. (cf. Stow 1935.) In Allium, the number of tillering and the time of flowering seem to be closely related to the elimination of the satellites.

\section{Summary}

1. The satellite of the nucleolar chromosome of Allium fistulosum is sometimes eliminated. The variety "Wakeginebuka" is heterozygous for deficiency of satellites $\left(\mathrm{SS}^{-}\right)$and some plants of the variety "Kujonegi" homozygous ( $\mathrm{S}^{-} \mathrm{S}^{-}$).

2. The meiosis, mitosis, and some characters of the variants and its progenies were studied.

3. The elimination of the satellite may occur through mitotic processes.

4. In the root-tip cells of one exceptional plants ( $\mathrm{SS}^{-}$), two different karyotypes were found in a chimeral state.

5. The effects of pyrogallol on mitosis were reinvestigated by the use of SSkaryotyped plants.

\section{Literature cited}

Haga, T. 1942. Nucleolus-chromosome relationship in Paris verticillata MB., with special reference to the presence or absence of a satellite. Cytologia, 12:479-485.

Haga, T. 1944. Meiosis in Paris I. Mechanism of chiasma formation. Journ. Fac. Sci. Hokkaido Imp. Univ. Ser. V, $5: 121-198$.

Kato, Y. 1954. Descriptive and experimental cytology in Allium II. Chromosome breakage in the seedling of Allium. Bot. Mag. (Tokyo). LXVII : 122-128.

Kihlmann, B. 1952. Induction of chromosome changes with purine derivatives. Symb. Bot. Upsal., XI. No. $4: 1-96$.

Ono, H. and Sakai, B. 1952. Intergeneric hybridization in Cichorieae, XI. On the diminution of the chromosome number in the $\mathrm{F}_{1}$ hybrid of Paraixeris denticulata and Lactuca squarrosa Cytologia, $17: 97-103$.

Therman-Soumalainen, E. 1949. The action of pyrogallol on secondary constriction. Hereditas, XXXV : $250-251$.

Tjio, J. H. 1951. Chromosome fragmentation by pyrogallol in Vicia faba. An. Aula Dei., 2 : $187-194$.

Stow, I. 1935. On the correlation between the satellite of chromosome and the leaf shape in Parideae from Hokkaido. Journ. Hokkaido Imp. Univ, ser V. $4: 31-46$. 